\section{ASD-GFP Vectors for In Vivo Expression Technology in Pseudomonas aeruginosa and Other Gram- Negative Bacteria}

BioTechniques 24:261-264 (February 1998)

\begin{abstract}
We describe the construction of promoter probe vectors designed for identification of bacterial genes induced in vitro and/or in vivo and for measurement of gene expression levels for in vivo expression technology. These plasmids use the Pseudomonas aeruginosa aspartate $\beta$-semialdehyde dehydrogenase (asd) gene as a selectable marker and $\beta$-galactosidase (pIVPRO, $10.88 \mathrm{~kb}$ ) or mutant green fluorescent protein with enhanced fluorescence properties (mut3GFP, pIVET-GFP, $5.48 \mathrm{~kb}$ ) as reporter gene systems. The proposed strategies can be adapted for use in most Gram-negative bacteria.
\end{abstract}

\section{INTRODUCTION}

In vitro laboratory conditions do not perfectly mimic the environments encountered during an infection (18). In parallel, most virulence-associated genes are not constitutively expressed but rather coordinately regulated by environmental signals. Therefore, strategies have been designed for selection of genes uniquely expressed or induced in vivo, but not detectable by in vitro methods $(2,12,16,17)$.

Aspartate $\beta$-semialdehyde dehydrogenase (ASD) is an essential enzyme in the biosynthesis of diaminopimelate (DAP), a component of the peptidoglycan in the cell wall of Gram-negative bacteria (23). The product of the asd gene is part of the biosynthetic pathway for lysine, methionine and threonine (27). In the absence of DAP, ASD-deficient bacteria undergo cell lysis. Because mammalian tissues contain no DAP, the asd gene could provide stringent selection in in vivo expression technology (IVET) $(8,9)$. Vaccine delivery systems based on stringent requirements for DAP have previously been used for in vivo complementation of ASD-attenuated bacteria $(8,20,32)$.

The green fluorescent protein (GFP) from the bioluminescent jellyfish $A e$ quorea victoria has been cloned and expressed in bacteria, and its three-dimensional structure has been determined at $1.9-\AA$ resolution (21). The wild-type GFP of 238 amino acids absorbs blue light at $395 \mathrm{~nm}$ (with a minor peak at $470 \mathrm{~nm}$ ) and emits green light at $509 \mathrm{~nm}$ maximum (a shoulder at $540 \mathrm{~nm})(19,21,22,30)$. Mutant GFPs have enhanced fluorescence emission, higher solubility and improved chromophore formation kinetics $(4,5)$. GFP has excellent characteristics for natural fluorescence in eukaryotes and in prokaryotes without exogenous substrates or cofactors and is stable with minimal photobleaching at $470 \mathrm{~nm}$. In vivo fluorescence persists in formaldehyde-fixed specimens, and GFP is known as an excellent reporter $(1,3,6,7,11,15,28,31)$.

IVET vectors were designed for identification and qualitative estimation of in vivo- and/or in vitro-induced genes. The ASD-GFP and ASD-LACZ phenotypes are alternatives to thymine and purine metabolism selection schemes found in previously described pIVET1 and pIVET2 vectors $(16,17)$.

\section{MATERIALS AND METHODS}

\section{Bacterial Strains and Plasmids}

Bacterial strains and plasmids used for genetic constructs have been described previously $(4,6,13,14,16,17$, 25,26,29).

\section{In Vitro DNA Manipulations}

As shown in Figure 1, directional cloning of the 1.13-kb XbaI/KpnI DNA fragment encoding the promoterless asd gene from pPS445 into the mobilizable suicide vector pGP704 generated pMON2200 $(13,15)$. The $6.1-\mathrm{kb}$ SphI DNA fragment containing the promoterless lacZY gene from pIVET1 was subcloned into pMON2200 in the same orientation as asd and generated pIVPRO. The 0.74-kb KpnI/SphI DNA fragment (mut3 $g f p$ gene) from pKEM 


\section{Short Technical Reports}

$(4,28)$ plasmid was cloned into pMON2200 previously digested with KpnI/SphI, creating pIVET-GFP.

\section{Construction of Libraries}

Psendomonas aeruginosa PAO1 genomic DNA was partially digested with MboI, size-selected by agarose gel electrophoresis (1-4 kb) and cloned into the $B g l \mathrm{II}$ site $5^{\prime}$ to the promoterless asd-lacZY (pIVPRO) or asd-mut $3 g f p$ (pIVET-GFP). The random pool of fusions was initially maintained in $E$. coli DH5 $\alpha(\lambda$ pir $)(14,16)$ and transformed in $E$. coli SM10( $\lambda$ pir) (13) for bacterial conjugation to $P$. aeruginosa ( $\Delta a s d:$ : $\mathrm{Gm})$.

\section{Selection of Recombinants}

E. coli electroporants were selected on TSA plates (Difco, Detroit, MI, USA) containing $100 \mu \mathrm{g} / \mathrm{mL}$ ampicillin. Plasmid pPS445 was maintained in $E$. coli $\mathrm{SH} 309$ ( $\Delta a$ asd) (24) and plasmid pKEM derivatives in $E$. coli DH5 $\alpha^{\mathrm{TM}}$ (Life Technologies, Gaithersburg, MD, USA). Plasmids pGP704, pMON2200, pIVET-GFP and pIVPRO were maintained in $E$. coli $\mathrm{DH} 5 \alpha(\lambda$ pir), and $E$. coli SM10( $\lambda$ pir) was used for conjugation. Pseudomonas libraries were selected on TSA-containing carbenicillin $(\mathrm{Cb} ; 500 \mu \mathrm{g} / \mathrm{mL})$, either with $500 \mu \mathrm{g} / \mathrm{mL}$ DAP or without DAP. $\beta$ Galactosidase expression was estimated by plating libraries on TSA plates containing $40 \mu \mathrm{g} / \mathrm{mL} \quad$ 5-bromo-4chloro-3-indolyl- $\beta$-D-galactopyranoside (X-gal). Colonies were examined under UV light for GFP expression.

\section{RESULTS AND DISCUSSION}

\section{Design and Properties of pIVET- GFP and pIVPRO Vectors}

Plasmids were constructed as described in Materials and Methods using the pGP704 suicide vector having the R6K origin of replication and requiring pir-encoded $\pi$ protein, ampicillin resistance as a selectable marker and the RP4 mob for mobilization from $\mathrm{Tra}^{+}$ strains $(14,25)$. The final constructs are depicted in Figure 1. The vectors constructed in this study differed from the reported IVET vectors of Mahan et al. $(16,17)$ and Slauch et al. $(26)$ in various
Table 1. Comparison of Identity Values (\%) between the ASD Polypeptide Sequence of Pseudomonas aeruginosa with ASD from Other Bacterial Species ${ }^{\mathrm{a}}$

\begin{tabular}{|c|c|c|c|c|}
\hline & $\begin{array}{l}\text { Escherichia } \\
\text { coli }\end{array}$ & $\begin{array}{l}\text { Haemophilus } \\
\text { influenzae }\end{array}$ & $\begin{array}{l}\text { Bordetella } \\
\text { pertussis }\end{array}$ & $\begin{array}{c}\text { Neisseria } \\
\text { meningitidis }^{b}\end{array}$ \\
\hline P. aeruginosa & 68.3 & 65.9 & 67.9 & 67.6 \\
\hline E. coli & & 72.5 & 66.7 & 65.5 \\
\hline H. influenzae & & & 64.7 & 64.0 \\
\hline B. pertussis & & & & 66.4 \\
\hline \multicolumn{5}{|c|}{$\begin{array}{l}\text { aGenBank }{ }^{\circledR} \text { Accession Nos.: E. coli, V00262; H. influenzae, L45287 and } \\
\text { L42023; B. pertussis, X75813; N. meningitidis, Z14063; P. aeruginosa, } \\
\text { U11055. }\end{array}$} \\
\hline bPartial sequen & & & & \\
\hline
\end{tabular}

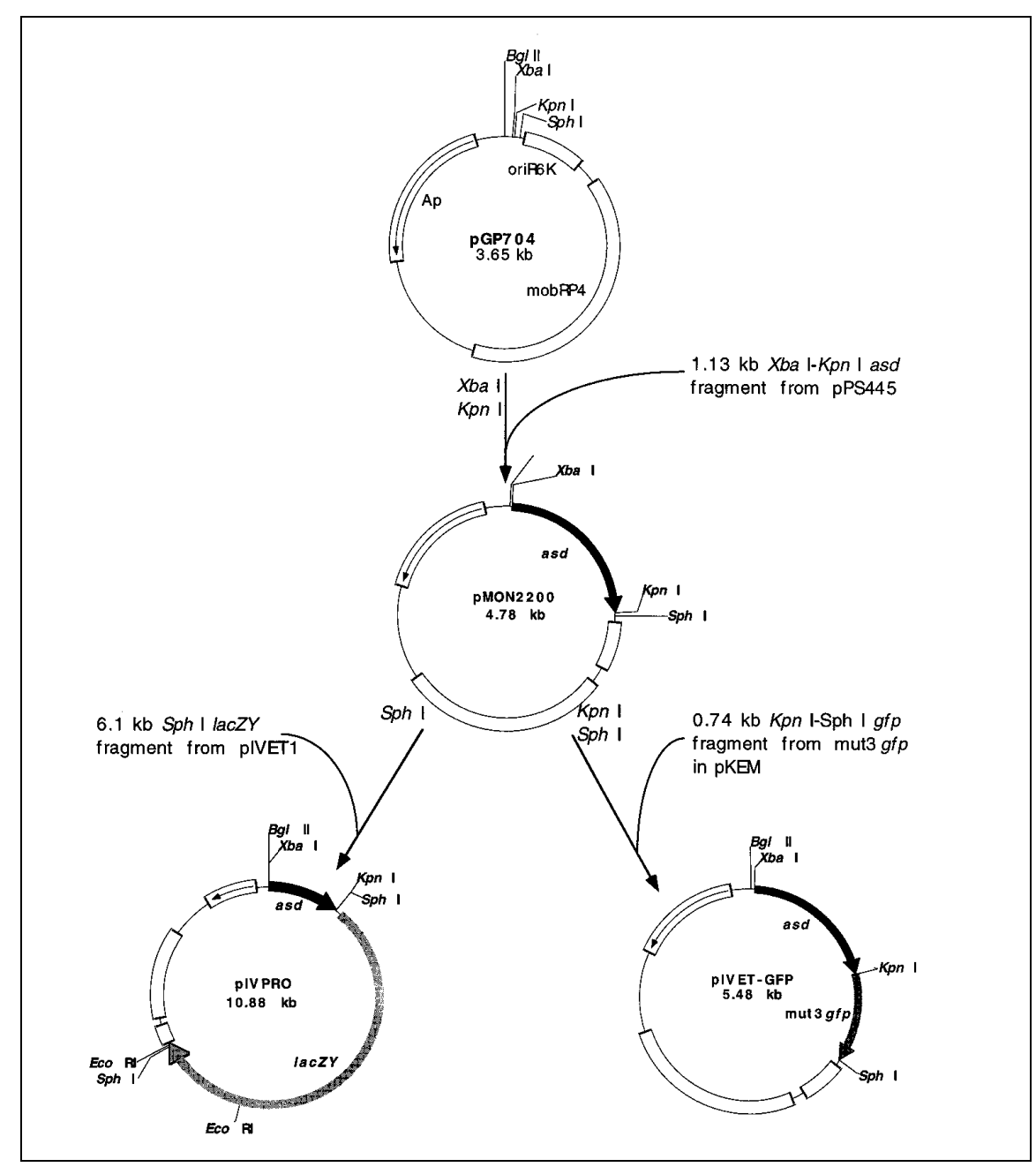

Figure 1. Construction of promoter probe vectors pIVET-GFP and pIVPRO. The locations of the ampicillin-resistance $\left(\mathrm{Ap}^{\mathrm{r}}\right)$ gene ("Ap"), plasmid R6K origin of replication ("oriR6K") and mobilization fragment ("mobRP4") constituting the suicide plasmid pGP704 are shown in open white boxes. The black arrow indicates the location and orientation of the promoterless $P$. aeruginosa asd gene. The gray arrow indicates the location and orientation of the promoterless $g f p$ gene, and the dark-gray arrow indicates the promoterless lacZY genes. 
aspects. Originally, pIVET1 and pIVET2 selection was based on in vivo complementation of purA and thy, respectively. The products of these genes are essential for purine and pyrimidine biosynthesis, and their absence severely attenuated growth in vivo. Although they proved useful and adequate for Salmonella typhimurium in a mouse model of septicemic infection $(16,17$, 26), there have been concerns about selection stringencies and potential leakiness in other bacterial systems. Not all types of infections would necessarily deprive bacteria of purines or pyrimidines. These nutrients could be scavenged by bacteria at sites of local inflammations or in tissues damaged by toxins. For plasmids pIVET-GFP and pIVPRO, the $P$. aeruginosa asd gene was chosen because: (i) ASD selection is stringent and non-leaky; (ii) DAP is absent from mammalian tissues, and bacterial asd mutants undergo rapid lysis; (iii) alignments of amino acid sequences of ASD from $P$. aeruginosa (13) with ASD polypeptide sequences from other Gram-negative bacteria confirm that ASD is conserved in evolution (Table 1); (iv) complete asd deletion mutants are available for $E$. coli (20,24), S. typhimurium $(8,20)$, Neisseria meningitidis (9) and $P$. aeruginosa (13); (v) the GC-rich $P$. aeruginosa asd is a heterologous system, thus minimizing the possibility of homologous recombination between the IVET asd gene and asd genes from the bacterial chromosome of an asd $^{-}$host strain.

The lacZY genes were chosen as IVET reporters for their sensitivity, reliability, ease of in vitro measurements and availability of $\Delta l a c$ host strains. However, the $6.1-\mathrm{kb}$ size of $l a c Z Y$ in pIVPRO hampers construction of representative genomic libraries and subsequent manipulations of fusion plasmids. In pIVET-GFP, the much smaller 740-bp mut3gfp gene was therefore utilized. Expression of mut3 $g f p$ was visualized by inspecting colonies on agar plates using an inexpensive UV light or by spectrophotometry of small samples in suspension. One advantage of ASDGFP IVET is the potential use of an automated fluorescence-activated cellsorting apparatus for measurements of GFP expression observed in vivo (4). Mutant GFP is detectable within $8 \mathrm{~min}$ after induction, compared to two hours for the wild-type enzyme, permitting studies of transient gene expression at early time points (4).

\section{Testing of Novel IVET Vectors}

The IVET system was tested by randomly cloning promoter-containing chromosomal $P$. aeruginosa PAO1 DNA fragments into the $B g I I I$ site $5^{\prime}$ to the promoterless asd-lacZY (pIVPRO1) or asd-mut3gfp (pIVPRO-2) genes. The random pool of fusions was transferred and integrated into a $\Delta a s d$ deletion strain of $P$. aeruginosa ( $\Delta a s d:$ : $\mathrm{Gm})$. The merodiploids were grown and selected on rich media containing carbenicillin, with or without DAP. The LacZY or GFP expression was assayed by plating libraries on TSA plates containing X-gal or by direct observation of the colonies under UV light irradiation, respectively. Growth on the DAP-containing medium of the random library resulted in mixed populations of $\mathrm{Lac}^{+} / \mathrm{Lac}^{-}$or $\mathrm{GFP}^{+} / \mathrm{GFP}^{-}$phenotypes. Growth on DAP-deprived medium of the same libraries resulted in the stringent selection of $\mathrm{Lac}^{+}$or $\mathrm{GFP}^{+}$ colonies, demonstrating that expression of the promoterless asd gene could alleviate the DAP requirement of a $\Delta a s d$ mutant by selecting for constitutively expressed promoters. The pool of fusions has also been challenged in various animal models. Fusion strains transcriptionally active in vivo were also obtained, and details will be reported elsewhere.

The constructs described here are IVET-based plasmid vectors for selection of genes differentially expressed or expressed solely in vivo. Some bacterial pathogens show tissue tropism and/or follow precise steps during infection. Using the pIVET-GFP and pIVPRO vectors, one should be able to detect patterns in gene expression or to determine the genetic response to environmental stimuli. Furthermore, the pIVET-GFP vector can be used in vivo and the expression monitored in real time without invasive procedures based on the GFP properties. pIVET-GFP derivatives expressing variants of GFP with altered absorption spectra and reemission levels will permit multiple IVET labelings. It is anticipated that the ASD-LACZ and ASD-GFP vectors will expand and/or complement the repertoire of $i v i$ genes obtained with the previously described IVET vectors $(5,10,11)$.

\section{REFERENCES}

1.Arigoni, F., K. Pogliano, C.D. Webb, P. Stragier and R. Losick. 1995. Localization of protein implicated in establishment of cell type to sites of asymmetric division. Science 270:637-640.

2.Camilli, A. and J.J. Mekalanos. 1995. Use of recombinase gene fusions to identify Vibrio cholerae genes induced during infection. Mol. Microbiol. 18:671-683

3.Chalfie, M., Y. Tu, G. Euskirchen, W.W. Ward and D.C. Prasher. 1994. Green fluorescent protein as a marker for gene expression. Science 263:802-804.

4.Cormack, B.P., R.H. Valdivia and S. Falkow. 1996. FACS-optimized mutants of the green fluorescent protein (GFP). Gene 173:33-38.

5.Delagrave, S., R.E. Hawtin, C.M. Silva, M.M. Yang and D.C. Youvan. 1995. Redshifted excitation mutants of the green fluorescent protein. Bio/Technology 13:151-154.

6.Dhandayuthapani, S., L.E. Via, C.A. Thomas, P.M. Horowitz, D. Deretic and V. Deretic. 1995. Green fluorescent protein as a marker for gene expression and cell biology of mycobacterial interactions with macrophages. Mol. Microbiol. 17:901-912.

7.Fey, P., K. Compton and E.C. Cox. 1995. Green fluorescent protein production in the cellular slime molds Polysphondylium pallidium and Dictyostelium discoideum. Gene 165:127-130.

8.Galán, J.E., K. Nakayama and R. Curtiss III. 1990. Cloning and characterisation of the asd gene of Salmonella thyphimurium: use in stable maintenance of recombinant plasmids in Salmonella vaccine strains. Gene 94:29-35.

9.Hatten, L.-A., H.P. Schweizer, N. Averill, L. Wang and A.B. Schryvers. 1993. Cloning and characterisation of the Neisseria meningitidis asd gene. Gene 129:123-128.

10.Heim, R., A.B. Cubitt and R.Y. Tsien. 1995. Improved green fluorescence. Nature 373:663-664.

11.Heim, R., D.C. Prasher and R.Y. Tsien. 1994. Wavelength mutations and posttranslational autoxidation of green fluorescent protein. Proc. Natl. Acad. Sci. USA 91:1250112504.

12.Hensel, M., J.E. Shea, C. Gleeson, M.D. Jones, E. Dalton and D.W. Holden. 1995. Simultaneous identification of bacterial virulence genes by negative selection. Science 269:400-403

13.Hoang, T.T., S. Williams, H.P. Schweizer and J. Lam. 1997. Molecular genetic analysis of the region containing the essential Pseudomonas aeruginosa asd gene encoding aspartate- $\beta$-semialdehyde dehydrogenase. Microbiology 143:899-907.

14.Kolter, R., M. Inuzuka and D.R. Helinski. 1978. Trans-complementation-dependent re- 
plication of a low molecular weight origin fragment from plasmid R6K. Cell 15:11991208.

15.Kremer, L., A. Baulard, J. Estaquier, O. Poulain-Godefroy and C. Locht. 1995. Green fluorescent protein as a new expression marker in mycobacteria. Mol. Microbiol. 17:913-922.

16.Mahan, M.J., J.M. Slauch and J.J. Mekalanos. 1993. Selection of bacterial virulence genes that are specifically induced in host tissues. Science 259:686-688.

17.Mahan, M.J., J.W. Tobias, J.M. Slauch, P.C. Hanna, R.J. Collier and J.J. Mekalanos. 1995. Antibiotic-based selection for bacterial genes that are specifically induced during infection of a host. Proc. Natl. Acad. Sci. USA 92:669-673.

18.Mekalanos, J.J. 1992. Environmental signals controlling expression of virulence determinants in bacteria. J. Bacteriol. 174:1-7.

19.Morin, J.G. and J.W. Hastings. 1971. Energy transfer in a bioluminescent system. J. Cell. Physiol. 77:313-318.

20.Nakayama, K., S.M. Kelly and R. Curtiss III. 1988. Construction of an asd ${ }^{+}$expressioncloning vector: stable maintenance and high level expression of cloned genes in a Salmonella vaccine strain. Bio/Technology 6:693697.

21.Ormö, M., A.B. Cubitt, K. Kallio, L.A. Gross, R.Y. Tsien and S.J. Remington. 1996. Crystal structure of the Aequorea victoria green fluorescence protein. Science 273:1392-1395.

22.Prasher, D.C., V.K. Eckenrode, W.W. Ward, F.G. Prendergast and M.J. Cormier. 1992. Primary structure of the Aequorea victoria green-fluorescent protein. Gene 111:229233.

23.Schleifer, K.H. and O. Kandler. 1972. Peptidoglycan types of bacterial cell walls and their taxonomic implications. Bacteriol. Rev. 36:407-477.

24.Schweizer, H.P., G. Sweet and T.J. Larson. 1986. Physical and genetic structure of the glpD-malT interval of the Escherichia coli $\mathrm{K}$ 12 chromosome. Mol. Gen. Genet. 202:488492.

25.Simon, R., U. Priefer and A. Puhler. 1983. A broad host range mobilisation system for in vivo genetic engineering: transposon mutagenesis in gram negative bacteria. Bio/Technology 1:784-791.

26.Slauch, J.M., M.J. Mahan and J.J. Mekalanos. 1994. In vivo expression technology for selection of bacterial genes specifically induced in host tissues. Methods Enzymol. 235:481-492.

27.Théze, J., D. Margarita, G.N. Cohen, F. Borne and J.C. Patte. 1974. Mapping of the structural genes of the three aspartokinases and of the two homoserine dehydrogenases of Escherichia coli K-12. J. Bacteriol. 117:133143.

28.Valdivia, R.H. and S. Falkow. 1996. Bacterial genetics by flow cytometry: rapid isolation of Salmonella typhimurium acid-inducible promoters by differential fluorescence induction. Mol. Microbiol. 22:367-378.

29.Vieira, J. and J. Messing. 1982. The pUC plasmid, an M13mp7-derived system for in- sertion mutagenesis and sequencing with synthetic universal primers. Gene 19:259-268

30.Ward, W.W., C.W. Cody, R.C. Hart and M. Cormier. 1980. Spectrophotometric identity of the energy transfer chromophores in Renil$l a$ and Aequorea green-fluorescent proteins. Photochem. Photobiol. 31:611-615.

31.Webb, C.D., A. Decatur, A. Teleman and R. Losick. 1995. Use of green fluorescent protein for visualisation of cell-specific gene expression and subcellular protein localization during sporulation in Bacillus subtilis. J. Bacteriol. 177:5906-5911.

32.Wu, S.G., D.W. Pascual, J.L. Vancott, J.R. McGhee, D.R. Maneval, M.M. Levine and D.M. Hone. 1995. Immune responses to novel Escherichia coli and Salmonella thyphimuri$u m$ vectors that express colonisation factor antigen-I (CFA/I) of enterotoxigenic Escherichia coli in the absence of the CFA-I positive regulator CFAR. Infect. Immun. 63:4933-4838.

We would like to thank John J. Mekalanos (Harvard University) for plasmid pGP704 and Brenda Cormack and Stanley Falkow (Stanford University) for the mut3gfp-containing plasmid. This work was supported by a grant to R.C.L. from the Canadian Cystic Fibrosis Foundation. R.C.L. is a Scholar of Exceptional Merit from the Fonds de la Recherche en Santé du Québec and funded by the Centers of Excellence via the Canadian Bacterial Diseases Network. M.H. was supported by a graduate studentship from the Canadian Cystic Fibrosis Foundation and in part by the Fonds pour la Formation de Chercheurs et l'Aide à la Recherche. M.J.M was supported by National Institutes of Health Grant No. AI36373, ACS Junior Faculty Research Award No. 554 and the Beckman Young Investigator Award. Address correspondence to Dr. Roger C. Levesque, Microbiologie Moléculaire et Génie des Protéines, Faculté de Médecine et Pavillon CharlesEugéne Marchand, Université Laval, Ste.Foy, QC, Canada G1K 7P4. Internet: rclevesq@rsvs.ulaval.ca

Received 13 March 1997; accepted 25 September 1997.
${ }^{2}$ M. Handfield, H.P. Schweizer1, M.J. Mahan'2, F. Sanschagrin, T. Hoang 1 and R.C. Levesque Université Laval Ste.-Foy, QC, Canada ${ }^{\text {I} C o l o r a d o ~ S t a t e ~ U n i v e r s i t y ~}$ Fort Collins, $\mathrm{CO}$ University of California Santa Barbara, CA, USA 